\title{
Research and Teaching Materials in Development Studies
}

\section{Martin J. Boodhoo}

The case for and the mode of undertaking research which is linked to the preparation of teaching materials ${ }^{1}$ in Development Studies ${ }^{2}$ is not recent. Yet it continues to be a problem that obsesses curriculum designers as is evidenced by the dearth of appropriate teaching materials on developing countries.

In this paper attention will be focused on some current trends and problems in the development of teaching materials through research undertaken in developing countries. Recent developments in the Department of Administrative Studies (DAS), University of Manchester, will be used, though not exclusively, as a frame of reference, for the ways in which the subject matter and methodology of social science research can contribute to development studies, whether conducted in developed or developing countries.

It has become commonplace at almost every gathering of teachers or practitioners in developing countries to conclude with a recommendation to revamp the education systems both in content and process to reflect indigenous values, problems and aspirations. International forums and secretariats go even beyond this to call, for example, for radical changes in the world's social and economic order. It was even bluntly suggested at the Conference of Directors of Research held at Abidjan in August 1974 that European institutions ". . . should get out of the development business"3. Such responses would suggest that the methods used and subject areas chosen for research and teaching in the past are inappropriate to current development objectives and strategies. Furthermore, the change in stance in developed and developing countries can be attributed to the urgent need for research and teaching programmes to mirror new perspectives in social and economic development rather than esoteric

1 Teaching materials in the context of this discussion refer principally to documented materials i.e. monographs and research findings, case and comparative studies evaluation analyses, simulation exercises, film and film strips, video tapes and development games.

2 Development studies in this paper refer to study programmes of an interdisciplinary nature in the social sciences. This definition is similar to that adopted by the recently constituted European Association of Development Research. and Training Institutes (EADI), Vienna, Austria.

3 Report of Proceedings of Conference of Directors of Research held in Abidjan in August 1974. pursuits unrelated to the stark realities of underdevelopment.

Let us look briefly at the teaching of public administration. Until the last decade or so the curriculum of public administration studies in many institutions was based on the use of texts and other source materials that had a traditional law and order orientation or were biased towards a theoretical as opposed to a practical approach (Adedeji, 1969: 451-64). In the post-independence period, policy makers in many Third World countries have emphasised the developmental approach i.e. study of the social sciences that has some direct relevance to social and economic problems facing a country or region, and where expeditious solutions can be found (Adedeji, 1969, UNECA, 1973). But it is in this area, unfortunately, that there is an acute shortage of reliable and relevant teaching materials.

One way of bridging this gap is through empirical research which can make a significant contribution to the enrichment of development studies, provided it is undertaken on a collaborative basis 4 . Collaboration in research and training in the past, however, sufferered from a number of imbalances: the partnership was an 'unequal' one, and the subject area selected did not reflect the priorities of the poorer countries. As Samir Amin has pointed out:

"Some development research currently being conducted in the industrialised countries or resulting from collaboration between institutions in these countries and those in the Third World appears as a form of academic imperialism. It adds prestige to researchers in the former leaving little benefit, either academic or practical, to the researched country. Any collaboration between unequal partners inevitably leads to domination by the better equipped, better financed and better trained partners. The reaction to this kind of domination has even led to questioning the legitimacy of foreign scholars to concern themselves with problems of Third World countries. Many governments and scholars in Third World countries have grown sensitive to this 'intrusion' of foreign social scientists into their problems" (Amin, 1975:2).

4 For an excellent discussion on the problems and prospects of collaboration see Amin et al, 1977. 
In the light of such observations it is not surprising to learn that a number of developing countries -notably India, Kenya, Malawi, Malaysia, Tanzania and Trinidad \& Tobago - have formalised and tightened up the procedure for carrying out research in their countries both by local and foreign scholars.

These reactions have not gone unnoticed. In Sweden, following the report of a Royal Commission appointed by the Ministry of Education in April 1971, the following principles were enunciated to ensure that the results of development research have some relevance to the developing countries concerned:

-'problem orientation', that is the research target, is to provide a solution for a particular problem in a given society;

-inter- and multi-disciplinary scientific cooperation in view of the complex nature of underdevelopment;

-value relevance, which guarantees that the aim of the research is to change the conditions of under-development;

-a focus on the developing countries in order to alleviate the disadvantageous position of the developing countries in research cooperation and to promote a more egalitarian relationship.

In brief, according to the Commission, the aim of Swedish support to development research should be ". . . to produce knowledge which will increase the ability to identify, understand and master development problems" (SIDRC 1975:2).

In Britain also the Economic and Social Committee for Overseas Research (ESCOR) of the Ministry of Overseas Development stipulates two similar pre-conditions, inter alia, for supporting research in developing countries:

-that the project will generate data or findings which should have explicit practical relevance to the country concerned;

- that the research should be undertaken with the approval of the government or other agency involved. 5

In recent years joint collaboration between researchers in the UK and in developing countries has been encouraged.

International and bilateral aid programmes (e.g. U.N. agencies, Canada, the Netherlands) have also recently stressed the necessity for relating development aid and investigations to the fundamental issues of development on a more egalitarian

5 See copy of conditions governing ESCOR applications. basis. In spite of these efforts, there are still misgivings in many developing countries: Dudley Seers, Chairman of the European Association of Development and Training Institutes, reported recently that some developing countries wish for a period of 'silence' during which ". . . they would be free to think out their own problems without too much pressure from 'developed' countries" (EADI, 1976:ii).

What appears abundantly clear, is that development research will have to have a strong applied orientation on a basis of joint and equal partnership, rather than fulfilling the personal or institutional aspirations of the grand theorist. A theoretical framework is always desirable, but in the light of limited resources and demands for action research to meet grass-root problems, basic research may have to be deferred or spread over a longer period of time. ${ }^{6}$

The main focus of this short paper is not to discuss the problems of development research but to indicate how empirical research, if it meets the basic criteria discussed earlier, can be used to prepare teaching materials to enrich development studies.

With these problems in mind the Department of Administrative Studies at Manchester set up a research project in 1973 to update its knowledge and understanding of public administration in developing countries, and to identify and prepare appropriate teaching materials. The aims of the project were:

- to undertake research in selected areas of public administration and related subjects and prepare teaching materials that can be used with some regularity within the training and educational programmes of the Department;

- to make a study of the relevant research currently being done and recently published both in industrialised and developing countries and to ascertain how this could be adopted or used; - to conduct enquiries on teaching methods, course structure, curriculum development and content, and assess their suitability for new and existing programmes;

- to stimulate and sustain interest of staff members and individuals and institutions overseas in the research and development of appropriate teaching materials through discussions, correspondence and collaborative efforts;

-to devise a system of indexing and documentation to build up a Teaching Materials Bank.

6 This is not to suggest that such research should be overlooked by developing countries for strategic or other reasons. Indeed Brazil and India already undertake research of this 
A major task for anyone concerned with development studies is how to keep abreast with events in developing countries. Past professional experience and high academic qualifications are not in themselves adequate resources for grappling with the current and seemingly intractable problems of national development. Teachers in the social sciences whether in centrally-planned or mixed economies must demonstrate their understanding of the urgent problems of political, administrative, economic or social change.

This concern to shape programmes to meet current needs is not confined to developing countries. Recently Sir Alex Smith, Chairman of the UK Schools Council, speaking at a conference of the National Association of School-Masters, stated that: "For many, education had become an industry on its own, a self-servicing, selfperpetuating industry to provide ever expanding opportunities for enhancing the career prospects of educators, and rejecting any serious economic responsibility" (Times, 1976) (my emphasis). This view is in consonance with that of President Nyerere of Tanzania when he indicated at the opening of the University of Dar es Salaam that: "Students must learn to anticipate the kinds of problems which might arise . . . they must have their minds orientated towards solving such problems; analysis has to be followed by action and University education must lead to a positive and constructive approach to the difficulties which might face our nation in the future" (Nyerere, 1973: 199-200).

Development studies programmes cannot create effective learning situations unless a substantial part of the teaching materials used reflect realistic problems and issues as they exist in the community. To meet these challenges the DAS research project concentrated on the building of a Teaching Materials Bank through the preparation of case and comparative studies, development games, simulation exercises and other forms of teaching materials with the aim of stimulating and encouraging staff members and study fellows to improve their understanding of development issues.

Because of the diversity of countries in which research may be undertaken and of the wide range of subject areas the selection of research topics and countries in which research could be most fruitfully undertaken has not been easy. The following guidelines provided a workable framework:

-the geographical areas selected should reflect those countries from which DAS study fellows have been drawn, to ensure that there would be some established channels of contact at both personal and official level to generate the data necessary to cover the subject areas of research;

- the sample of countries and subjects selected could be regarded as representative of the population of developing countries from which study fellows have been and are likely to continue to be drawn, so as to avoid undertaking a study which might have historic but not contemporary or predictive import;

- the research as a whole could be adapted for use in one or more of the study programmes as background information, case study or syndicate materials; and possibly, if the investigation is of some depth, for publication as monographs or journal articles to achieve wider circulation;

-local support should be enlisted, wherever possible, from academics, administrators, research institutions, past study fellows, or other suitable bodies, so that both the exercise and the final product (teaching materials, monographs, etc.) could be of mutual benefit to DAS and the country concerned.

The choice of countries, selection of suitable topics and the enlisting of collaboration is a patience-testing task. Experience has shown that it is time-consuming, expensive (when research funds are scarce), can give rise to prolonged academic discussions, and tedious, delicate and sometimes abrupt correspondence. In sum, however, DAS has completed a number of research studies and laid the foundations for a continuing Teaching Materials Bank for use by staff members, study fellows and other interested bodies both here and abroad.

But what can an institution like DAS located in the West offer to multi-national, multi-cultural groups of students? While it is undeniable that public administration systems around the world differ from one another in several ways, experience has shown that nearly all share some characteristics. At first sight the differences between countries in Asia, Africa and Latin America seem too great to allow for any common study experience among students of all these regions. Because of the many common administrative features and development orientations in public and semi-public administrative systems, however, a closer examination suggests that it does make sense to enrol in a public administration study programme, students from a wide variety of countries.

The underlying justification for bringing together multi-national groups is that the study programmes at the DAS are based on a learning process which seeks to relate the theoretical know- 
ledge acquired to practical or simulated situations. Furthermore, such groups of mature experienced students learn together a range of alternative ideas and approaches to help them to improve the effectiveness of their public administration systems and their own professional skills as administrators within those systemis. To this end they may often learn more from each other than from the teaching staff; and the staff may often learn as much from the study fellows as they seek to impart.

It was the unique content of the study programmes, the multi-cultural nature of the participants, and the need to link theory and practice in public sector administration that motivated the Department to embark on a research programme to identify and develop new teaching materials. To ensure that effective learning situations are created and maintained a number of core elements should be borne in mind in the preparation of teaching materials. First, teaching materials should reflect a concrete situation which forms the basis for a realistic approach to the exercise. The data and background information given should not only be adequate but reliable in order to assist in the identification of significant and related issues.

Second, the subject area chosen for study should be relevant to the kinds of problems that administrators face in their work situation. In many training institutions in industrialised countries there is an acute shortage of teaching materials on developing countries, and as a result the recourse to materials based on advanced industrialised societies has inhibited rather than encouraged active group inter-action. Many trainees have, therefore, considered such sessions a waste of time.

Third, to sustain group interest, it is necessary to use materials that have some contemporary as opposed to historic significance. Administrators have to face the problems of the moment and plan for the future; historical information should therefore be incidental. (This does not suggest that an historical orientation is unimportant or unnecessary). The motivation to learn is enhanced when the teaching material presented is contemporary, emphasises applicability and indicates the advantages that can be derived and the likely problems associated with its application.

Finally, the type of material selected should be representative, especially if the group is international. This does not mean it should be random, as this would negate the distinctiveness of the material, especially if it is a case study; but it should reflect the kinds of problems that many developing countries face, e.g. strategies for decentralisation in rural development, public policy analysis, public sector management, public accountability. An element of representativeness avoids the oft heard criticisms of a study programme being slanted towards a particular cultural or geographical area or a particular aspect of academic discipline.

A final lesson seems to be that one should avoid model prescription. Kamla Chowdhry, speaking on management education in India, said: "It seems to me like good business managers we should look at significant trends in the environmient, understand the implications of these trends on the shape of management education in India and develop (suitable) strategies for research and teaching ..." (Chowdhry, 1976:28).

In addition to the development of teaching materials, there are other pay-offs in development research:

-it is a two-way (sometimes multi-) traffic to improve the capacity of developing countries to tackle problems at the grass-root level;

-empirical research can provide inputs for policy-makers in terms of data, findings, analyses, and outcomes of alternative courses of action and so base decision-making more on 'evidence' than on intuition or hunches;

- such exercises enable participants to improve their research ability and provide an excellent training ground for both academics and practitioners;

-this type of research encourages local institutions to become more conscious of the need to initiate and relate research to development issues and development studies;

-researchers and planners from industrialised societies become more aware of real domestic issues in developing countries and so provide a better climate for channelling aid, planning academic programmes and undertaking researcb with more respect for local values, aspirations and institutions.

Research findings have shown that in order to maintain realistic and relevant development studies programmes the issues of social change must be presented objectively through empirical research results and not on theoretical models. Such an approach could be found objectionable to individual researchers, research foundations or even governments. One needs to be diplomatic and non-abrasive in discussing issues and defining research topics, but to use such subtleties under the guise of being agreeable or "to conform" 
could lead to a situation that is not only disillusioning to students of development studies but could also tempt critics to say that such an exercise is a mere statistical contribution to aid programmes measured in monetary but not in real terms.

No one would deny that there is still a gap between industrialised and developing countries, but there seems to be a growing consensus among research and teaching institutions in many countries for a more objective approach to development research on a genuine collaborative basis. It holds great promise as an appropriate springboard for both the enrichment of development studies and the making of a contribution to the improvement of social and economic conditions in LDCs. It is not so much the ability but the willingness to maintain one's capacity to respond to new priorities and perspectives that will determine whether or not we run the risk of becoming irrelevant in our approach to development research and training.

\section{References}

Adedeji, Adebayo, 1969, 'Training for what? A Review of the Development and Problems of Administrative Training in Africa', in Public Administration, Vol. 47 (Winter)

Amin, Samir, et al, 1975, 'New forms of collaboration in development research and training', in International Social Science Journal, Vol. XXVIII, No. 4.

Chowdhry, Kamla, 1976, 'Management Education in India: Emerging Trends', in Indian Management, January

EADI, 1976, Bulletin, No. 3.

Nyerere, J.K., 1973, Speech at Opening of the University of Dar es Salaam in 1970, Speeches by Nyerere.

Swedish International Development Research Council (SIDRC), 1975, handout, September

Times, 1976, December 30

UNECA, 1973, Administration and Management in Africa. 